\title{
A single simple position for ultrasound assessment of both common extensor and common flexor origin at the elbow
}

\author{
Ahmed Abogamal ${ }^{1,2^{*}}$ (D), Saad Ghanem ${ }^{1}$ and Hatem Saad ${ }^{1}$
}

\begin{abstract} 0 to 10 , includes the following points:

- Time needed to examine the tendon in minutes,

- Difficulty in maintaining the probe contact to the skin,

- Difficulty in getting good image of the tendon,

- The overall impression of simplicity.
\end{abstract}

Objective: Is to evaluate the simplicity of $90^{\circ}$ flexion/neutral position for ultrasonography assessment of both common extensor and common flexor origins in comparison with the standard position.

Material and methods: A standard questionnaire was distributed on 50 trainees, rheumatologists with No previous experience or training in ultrasonography. (They) were attending musculoskeletal training workshops at AL-Azhar rheumatology department musculoskeletal ultrasonography unit in 2016. Each participant then (was) asked to practice US examination of both common extensor and common flexor origins in both positions and then fill four questionnaires, two (of which are) for common flexor and (the other) two (are) for the common extensor origins, in the standard and the other proposed single position. Each questionnaire (whose) answer was graded on scale from

Results: Descriptive analysis of the questionnaire results shows that the participants favors the single position in all questionnaire parameters. Comparing means of the four questionnaire parameters in both positions shows highly significant difference in the four parameters at the level of both common flexor and extensor origins in favor of the single position as $p>0.005$.

Conclusion: The 90 degree flexion/neutral position appears to be simpler than the standard position for ultrasonography assessment of common extensor and common flexor tendons at the elbow.

Keywords: Elbow, Ultrasonography, Common flexor, Common extensor

\section{Introduction}

Elbow pain represents a frequent complaint that encountered in the rheumatologist daily practice, and ultrasonography (US) can efficiently support the clinical examination by much valuable information about ligaments, synovium, joint space, and tendon insertions [1-4].

Pain and inflammation at the common extensor and common flexor origins are frequently responsible for pain

\footnotetext{
* Correspondence: ahmedfathy15@yahoo.com

${ }^{1}$ Rheumatology Department, Al-Azhar Faculty of Medicine, Cairo, Egypt

${ }^{2}$ Cairo, EGYPT
}

\section{actoon}

around the elbow and both US can readily assess them to detect any tendon or insertion line abnormalities [1-4].

As with all other imaging modalities and regions, US examination of the elbow requires proper orientation of the structure examined, positioning of the patient, and efficient training of the examiner [4-6].

.The standard position for US assessment of the common extensor and common flexor origins is the lateral humero-radial longitudinal scan (along lateral epicondyle) and the medial humero-ulnar longitudinal scan (along medial epicondyle) with the patient extended elbow [7].

(c) The Author(s). 2019 Open Access This article is distributed under the terms of the Creative Commons Attribution 4.0 International License (http://creativecommons.org/licenses/by/4.0/), which permits unrestricted use, distribution, and reproduction in any medium, provided you give appropriate credit to the original author(s) and the source, provide a link to the Creative Commons license, and indicate if changes were made. The Creative Commons Public Domain Dedication waiver (http://creativecommons.org/publicdomain/zero/1.0/) applies to the data made available in this article, unless otherwise stated. 
During this position, maintaining and stabilizing the probe in good contact with the patient skin may encounter some difficulties especially for the beginners at initial US basic training because of normal anatomical angular articulation between the humerus, ulna, and radius [8].

We proposed another positon for the assessment of both common extensor and common flexor origins by positioning the probe longitudinally pointing to the medial and lateral epicondyles, parallel to radius and ulna while the patient in the same position for triceps tendon assessment Posterior scan $\left(90^{\circ}\right.$ flexion/neutral position).

In that position we could avoid the effect of articulation angle of the elbow, easily maintain good contact between the probe and the skin, and obtain a good picture for three tendons insertions in one patient position.

So the aim of the work is to evaluate the simplicity of $90^{\circ}$ flexion/neutral position to assess both common extensor and common flexor origins in comparison with the standard lateral humero-radial longitudinal scan and the medial humero-ulnar longitudinal scan.

\section{Subjects and methods}

A standard questionnaire distributed on trainees while attending basic musculoskeletal training workshops at Al-Azhar Rheumatology department MSUS unit in 2016.

\section{Inclusion criteria}

All the participants are Rheumatologists, with No previous experience or training in ultrasonography and blinded about the standard position for common extensor and common flexor origins US assessment.

After approval from departmental ethical committee, a group of 50 trainees accepted to participate in our study. Each participant was instructed about US examination of both common extensor and common flexor origins in both positions by two different instructors one for each position: The standard lateral humero-radial longitudinal scan and the medial humero-ulnar longitudinal scan. 7, and the $90^{\circ}$ flexion/neutral position with positioning the probe longitudinally pointing to the medial and lateral epicondyles.
All examinations were conducted using the LOGIQ e ultrasonography system of GE with $12 \mathrm{~L}$ linear probe.

Each participant then (was) asked to practice US examination of both common extensor and common flexor origins in both positions and then fills four questionnaires, two for common flexor and two for the common extensor origins, in the standard and the other proposed single position.

Each questionnaire, whose answer was graded on scale from 0 to 10 , includes the following points: Time needed to examine the tendon in minutes, Difficulty in maintaining the probe contact to the skin (0 the least difficult), Difficulty in getting good image of the tendon ( 0 the least difficult), and The overall impression of simplicity ( 0 the most simple).

\section{Data analysis}

Data were entered, organized, tabulated and analyzed using the standard computer program SPSS version 18. Quantitative data were expressed as Mean $\pm \mathrm{SD}$. Student t-test was used to measure the difference between means of two quantitative groups, with the significant level set at 0.05 .

\section{Results}

Descriptive analysis of the questionnaire results shows the Time needed to examine the tendon was $2.63 \pm 1.09$, $3.32 \pm 0.89,2.70 \pm 1.25,4.44 \pm 0.93$, for Common extensor single position, Common extensor standard position, Common flexor single position and Common flexor standard position respectively (Table 1, Figs. 1, 2, and 3).

While difficulty in maintaining the probe contact to the skin was $2.50 \pm 1.19,4.88 \pm 0.92,2.54 \pm 0.93$, $5.48 \pm 1.34$, for Common extensor single position, Common extensor standard position, Common flexor single position and Common flexor standard position respectively (Table 1 , Fig. 1 ).

Difficulty in getting good image was $3.12 \pm 0.74$, $5.54 \pm 1.09,3.12 \pm 0.77,4.56 \pm 1.67$, for Common extensor single position, Common extensor standard position, Common flexor single position and Common flexor standard position respectively (Table 1, Fig. 1).

The overall impression of simplicity of the position was $2.72 \pm 0.83,5.52 \pm 1.26,3.08 \pm 1.08,5.20 \pm 1.23$, for Common extensor single position, Common extensor

Table 1 Shows descriptive analysis of the questionnaire results

\begin{tabular}{|c|c|c|c|c|c|c|c|c|}
\hline & \multicolumn{2}{|c|}{$\begin{array}{l}\text { Common extensor } \\
\text { new position }\end{array}$} & \multicolumn{2}{|c|}{$\begin{array}{l}\text { Common extensor } \\
\text { standard position }\end{array}$} & \multicolumn{2}{|c|}{$\begin{array}{l}\text { Common flexor } \\
\text { new position }\end{array}$} & \multicolumn{2}{|c|}{$\begin{array}{l}\text { Common flexor } \\
\text { standard position }\end{array}$} \\
\hline & Mean & SD & Mean & SD & Mean & SD & Mean & SD \\
\hline Time needed to examine the tendon & 2.63 & 1.09 & 3.32 & 0.89 & 2.70 & 1.25 & 4.44 & 0.93 \\
\hline Difficulty in maintaining the probe contact to the skin & 2.50 & 1.19 & 4.88 & 0.92 & 2.54 & 0.93 & 5.48 & 1.34 \\
\hline Difficulty in getting good image & 3.12 & 0.74 & 5.54 & 1.09 & 3.12 & 0.77 & 4.56 & 1.67 \\
\hline The overall impression of simplicity & 2.72 & 0.83 & 5.52 & 1.26 & 3.08 & 1.08 & 5.20 & 1.23 \\
\hline
\end{tabular}




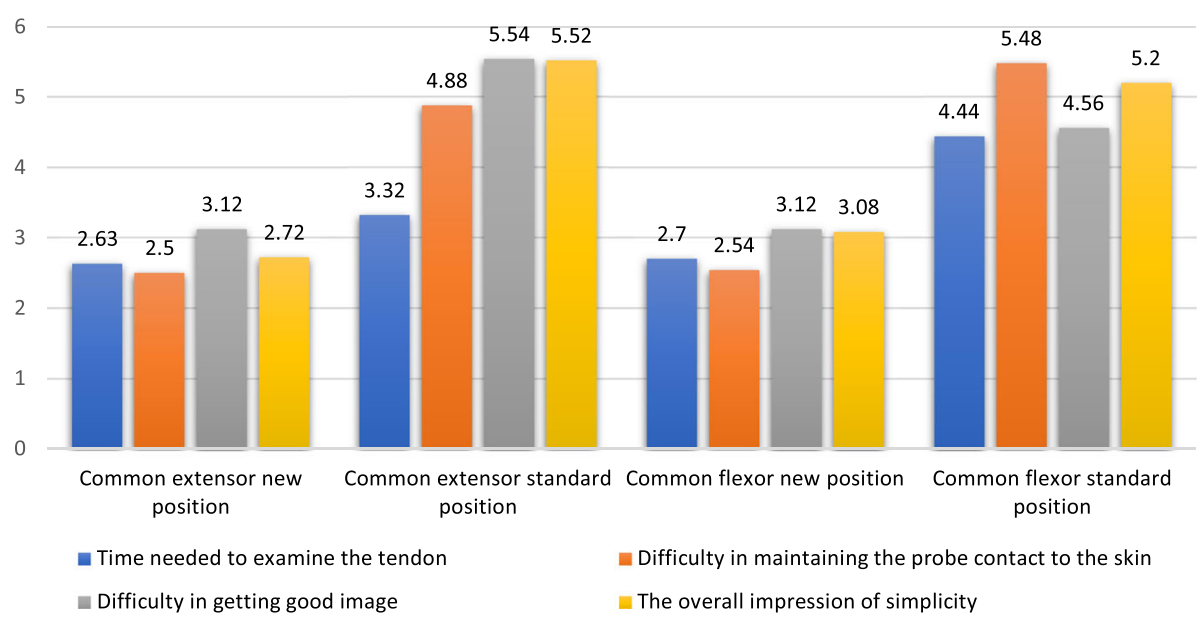

Fig. 1 Shows descriptive analysis of the questionnaire results

standard position, Common flexor single position and Common flexor standard position respectively (Table 1, Fig. 1).

Comparing means of the four questionnaire parameters in both positions shows highly significant difference in the four parameters at the level of both common flexor and extensor origins in favor of the single position as $p>0.005$ (Table 2).

\section{Discussion}

Elbow joint pathologies either articular or tendinopathies frequently present among many rheumatological disorders that requires precise assessment for proper diagnosis and treatment. With the sonographic revolution in field of rheumatology, US has proven to be sensitive and very efficient complementary tool for the clinical examination in the assessment of pathologies at the elbow joint $[6,9]$.
US assessment of the elbow joint and the tendons around are included in the EULAR online introductory course, and also has been present in all basic courses conducted or endorsed by the EULAR for US training $[7,10]$.

The articulations of humerus, radius, and ulna at the elbow are not going straight and undergoes many normal angulations. From lateral the Radial Neck- Shaft Angle which is the angle between a longitudinal line perpendicular to the articular surface of the radial neck and a longitudinal line along the radial shaft was measured. From medial is the Carrying Angle, which is the angle between the longitudinal axis of the humerus shaft and a longitudinal drawn along the shaft of the ulna $[8,11-13]$.

We hypothesis that these angulations may apply some difficulties during US assessment of the tendons on the medial and lateral elbow compartments, especially for the basic trainees in US. By applying flexion of the elbow

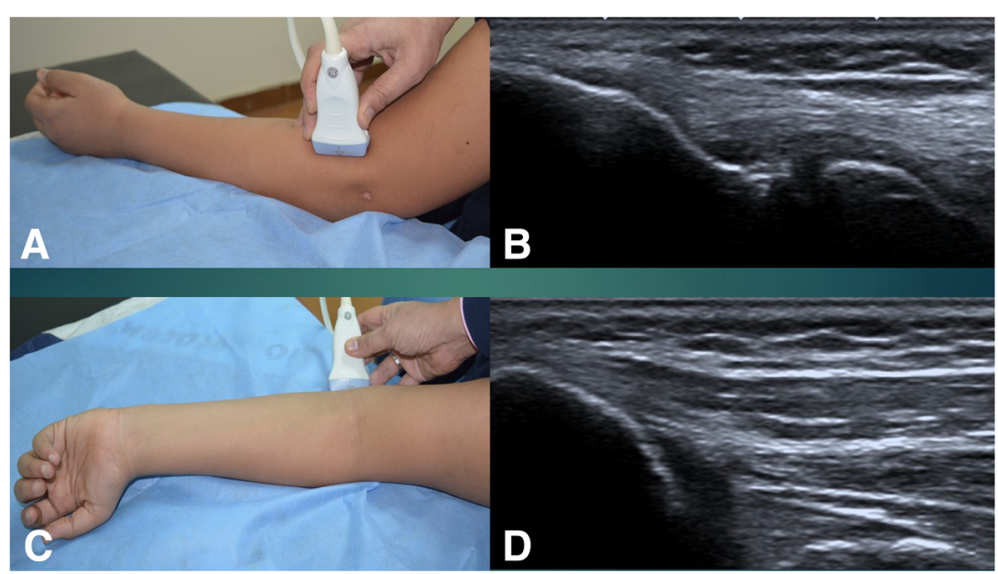

Fig. 2 Shows standard position and the corresponding US images, a: common extensor origin, b: corresponding US image for common extensor origin, c: common flexor origin, $\mathbf{d}$ : corresponding US image for common flexor 


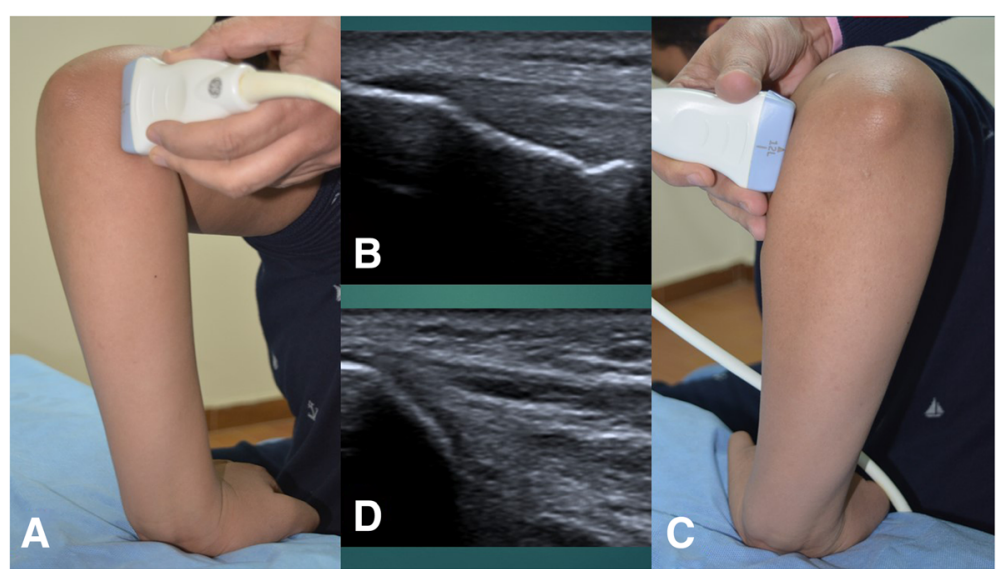

Fig. 3 Shows $90^{\circ}$ flexion/neutral position and the corresponding US images, a: common extensor origin, b: corresponding US image for common extensor origin, $\mathbf{c}$ : common flexor origin, $\mathbf{d}$ : corresponding US image for common flexor origin

to 90 degree in neutral position we can abolish this effect of these angles with stable patient elbow and simply applying the probe directly to the epicondyles parallel to the radius or ulna with good contact of the skin.

In that single patient position we can efficiently examine three tendons, the triceps posterior, common extensor laterally, and common flexor medially. This will reduce the time needed for examination and help the beginners to get confident assessment for tendons around the elbow in a more easy position.

In the current study we studied this rationale over a group of 50 young rheumatologists with no previous US experience, and analyzed their impression about both positions using four questions questionnaire.

Results Analysis shows that the participants defined the 90 degree flexion/neutral position to be simpler than the standard position at all parameters of the questionnaire.

Table 2 Shows comparison of all questionnaire parameters in both positions

\begin{tabular}{lll}
\hline & $\mathrm{t}$ & Sig. (2-tailed) \\
\hline Time N L - Time S L & -3.262 & .002 \\
Skin N L - Skin S L & -13.358 & .000 \\
Image N L - Image S L & -12.756 & .000 \\
Over N L - Over S L & -12.548 & .000 \\
Time N M - Time S M & -10.038 & .000 \\
Skin N M - Skin S M & -11.772 & .000 \\
Image N M-Image S M & -5.368 & .000 \\
Over N M - Over S M & -9.608 & .000 \\
\hline
\end{tabular}

Time Time needed to examine the tendon, Skin difficulty in maintaining the probe contact to the skin, Image Difficulty in getting good image, Over The overall impression of simplicity of the position, $N$ new position, $S$ standard position, $L$ common extensor, $M$ common flexor)
With the single position our participants spent less time to examine the tendons needed, and easily get a good skin contact to the probe foot plate with easier acquisition of good image for tendons.

The overall impression of our participants towards the simplicity of US assessment on the common extensor and common flexor tendons opted for the 90 degree flexion/neutral position rather than the standard position.

The results of our study were limited to junior rheumatologists, as they were the targeted group of our study, and extension studies including senior expert rheumatologists and radiologists are recommended for further generalization of our results. Another limitation of our study, was lack of comparing the accuracy of each position as regards the acquisition and detection of different tendon pathologies, this comparison in spite of its importance actually it was outside the objectives of our study which directed mainly to the simplicity of the single position for training of young rheumatologists, while the comparison requires further in depth trial including expert rheumatologists and radiologists. So further studies recommended to evaluates the reliability of 90 degree flexion/neutral position for the assessment of pathologies at the common extensor and common flexor tendons in comparison to the standard position.

According to our results we recommends the use of 90 degree flexion/neutral position for the assessment of common extensor and common flexor tendons especially for the basic training.

\section{Conclusion}

The 90 degree flexion/neutral position appears to be simpler than the standard position for assessment of both common extensor and common flexor tendons at the elbow. 
The study done under agreement of the Department ethical committee, and consent taken from all participants after detailed explanation of the study protocol.

The authors declares to have any conflict of interest with the publication, agrees with the journal publication terms and conditions. The all data and materials of the study are available and can be shared on request.

We declare having any financial aids, industrial support or grants and we would like to thank all trainees who shared in the study, the authorities in Al-Azhar University Hospitals, nursing staff and everyone who helped us to accomplish this work.

\section{Acknowledgements}

We declare having any financial aids, industrial support or grants and we would like to thank all trainees who shared in the study, the authorities in Al-Azhar University Hospitals, nursing staff of the Rheumatology department and everyone who helped us to accomplish this work.

\section{Authors' contributions}

AA: Professor Of Rheumatology Ai-Azhar Faculty Of Medicine, EULAR certified MSUS instructor and head of MSUS UNIT. The study idea, design, clinical part, writing, and submission. SG: Lecturer of Rheumatology, Al-AZHAR Faculty of Medicine. MSUS instructor participated in the clinical part of the study. HS: Lecturer of Rheumatology, Al-AZHAR Faculty of Medicine. MSUS instructor participated in the clinical part of the study. All authors read and approved the final manuscript.

\section{Ethics approval and consent to participate}

The study done under agreement of the Department ethical committee, and consent taken from all participants after detailed explanation of the study protocol.

\section{Competing interests}

The authors declares to have any conflict of interest with the publication, agrees with the journal publication terms and conditions. The all data and materials of the study are available and can be shared on request.

Authors declares any conflict of interest and any relevant funding agencies.

\section{Publisher's Note}

Springer Nature remains neutral with regard to jurisdictional claims in published maps and institutional affiliations.

Received: 10 December 2018 Accepted: 21 February 2019

Published online: 07 March 2019

\section{References}

1. Walz DM, Newman JS, Konin GP, Ross G. Epicondylitis: pathogenesis, imaging, and treatment. RadioGraphics. 2010;30:167-84.

2. Nirschl RP, Pettrone FA. Lateral and medial epicondilitis. W: Morrey BF (red.): master techniques in orthopedic surgery: the elbow. New York: Raven; 1994. p. 537-52

3. Faro F, Wolf JM. Lateral epicondilitis: review and current concepts. J Hand Surg Am. 2007:32:1271-9.

4. Delle Sedie A, Riente L, lagnocco A, Filippucci E, Meenagh G, Valesini G, Grassi W, Bombardieri S. Ultrasound imaging for the rheumatologist. VI. Ultrasonography of the elbow, sacroiliac, parasternal, and temporomandibular joints. Clin Exp Rheumatol. 2006;24(6):617-21.

5. Connell D, Burke F, Coombes P, McNealy S, Freeman D, Pryde D, et al. Sonographic examination of lateral epicondilitis. Am J Roentgenol. 2001:176:777-82.

6. Bianchi S, Martinoli C. Ultrasound of the musculoskeletal system. Berlin, Heidelberg: Springer -Verlag; 2007. p. 349-405

7. Wolfgang A. Schmidt, Sandrine Jousse Joulin, Marina Backhaus: Sonoanatomy scanning technique and basic pathology of the elbow module three. EULAR on-line course on Ultrasound, 2016.
8. Goldfarb CA, Patterson JMM, Sutter M, Krauss M, Steffen AJ, Galatz L. Elbow radiographic anatomy: measurement techniques and normative data. J Shoulder Elb Surg. 2012;21(9):1236-46.

9. Chumbley EM, O'Connor FG, Nirschl RP. Evaluation of overuse elbow injuries. Am Fam Physician. 2000;61(3):691-700.

10. http://www.eular.org/edu_course_ultrasound.cfm, at 23/12/16.

11. Johnson D, Ellis H. Elbow. In: Standring S, editor. Gray's anatomy: the anatomical basis of clinical practice. London: Elsevier Churchill Livingstone; 2005. p. 861-88.

12. Paraskevas G, Papadopoulos A, Papaziogas B, Spanidou S, Argiriadou H, Gigis J. Study of the carrying angle of the human elbow joint in full extension: a morphometric analysis. Surg Radiol Anat. 2004;26(1):19-23.

13. Snell RS. The upper limb. In: Snell RS, editor. Clinical anatomy by regions, 8th edition, Lippincott Williams \& Wilkins Health, Philadelphia; 2008. p. $510-20$.

\section{Ready to submit your research? Choose BMC and benefit from:}

- fast, convenient online submission

- thorough peer review by experienced researchers in your field

- rapid publication on acceptance

- support for research data, including large and complex data types

- gold Open Access which fosters wider collaboration and increased citations

- maximum visibility for your research: over $100 \mathrm{M}$ website views per year

At $\mathrm{BMC}$, research is always in progress.

Learn more biomedcentral.com/submissions 